\title{
Is Ankle Post-traumatic Osteoarthritis Inevitable after Malleolar Fractures?
}

\author{
Alexandre L Godoy-Santos ${ }^{1}$, Mario Herrera-Pérez ${ }^{2}$, Cesar de Cesar Netto ${ }^{3}$, André Wajnsztejn ${ }^{4}$, Vincenzo Giordano ${ }^{5}$
}

\begin{abstract}
The tibiotalar joint is one of the most prevalent intra-articular fracture sites in the human body, resulting in high rates of post-traumatic ankle osteoarthritis (PTOA). Studies have shown multifactorial causes for PTOA and highlight the importance of three determining factors for clinical outcomes after malleolar fracture: quality of joint reduction and fracture fixation, residual ligament instability, and initial damage to joint tissues-including chondral tissue, synovial tissue, and synovial fluid. This special article summarizes recent evidence of malleolar fractures treatment, with a main focus on important factors related to improve clinical outcomes in order to avoid post-traumatic ankle osteoarthritis (OA). Keywords: Ankle joint, Arthritis, Malleolar fracture.

Journal of Foot and Ankle Surgery (Asia Pacific) (2021): 10.5005/jp-journals-10040-1195
\end{abstract}

\section{INTRODUCTION}

Tibiotalar injuries are frequently evaluated by orthopedic trauma surgeons. In the United States, ankle sprains and fractures are highly prevalent, ${ }^{1}$ malleolar fractures represent $9-18 \%$ of all fractures in emergency services. ${ }^{2-4}$ The most prevalent etiological factor of ankle osteoarthritis $(O A)$ is tibiotalar joint fracture, added to other lesions around the foot and ankle, posttraumatic etiology represents about $78 \%$ of causes of ankle OA (Fig. 1). ${ }^{5-7}$

Secondary ankle OA due to other causes, such as rheumatoid disease, represents $13 \%$ of etiology, it was also more common than the primary $\mathrm{OA}(9 \%)^{4,5}$

Ankle OA affects approximately $1 \%$ of the population, some authors estimate an incidence of 30 cases per 100,000 population and this represents a share of $2-4 \%$ of all patients with OA. $^{6-9}$

Historically, the treatment for ankle fracture is anatomical reduction of the joint, initially with plaster and in 1984 Lane started to recommend surgery. ${ }^{10,11}$

Even with the evolution in the principles of management of ankle fractures, the estimated risk of clinical outcome with posttraumatic ankle osteoarthritis (PTOA) after 20 years is around $40 \%$, which is more frequent in Weber types $B$ and $C$ and fractures involving the posterior malleolus (PM).

The therapeutic options are limited for PTOA. Furthermore, the low comprehension of the molecular events involved in chondrocyte cell death limits the progress in this area of knowledge. $^{6-9}$

This article show recent evidence of malleolar fractures treatment.

\section{Determining Factors}

The three determining factors for clinical outcomes are:12,13

- Quality of joint reduction and fracture fixation.

- Residual ligament instability.

- Initial damage to joint tissues.
${ }^{1}$ Department of Orthopedic Surgery, Hospital das Clinicas HCFMUSP, Faculdade de Medicina, Universidade de Sao Paulo, Sao Paulo, Brazil; Department of Orthopedic Surgery, Hospital Israelita Albert Einstein, Sao Paulo, Brazil

${ }^{2}$ Orthopaedic Department, University of La Laguna, Tenerife, Spain

${ }^{3}$ Department of Orthopedics and Rehabilitation, University of lowa, lowa City, IA, USA

${ }^{4}$ Department of Orthopedic Surgery, Hospital Israelita Albert Einstein, Sao Paulo, Brazil

${ }^{5}$ Department of Orthopedic Surgery, Serviço de Ortopedia e Traumatologia Prof Nova Monteiro, Hospital Municipal Miguel Couto, Rio de Janeiro, Brazil; Department of Orthopedic Surgery, Clínica São Vicente, Rede D'or São Luiz, Rio de Janeiro, Brazil

Corresponding Author: Alexandre L Godoy-Santos, Department of Orthopedic Surgery, Hospital das Clinicas HCFMUSP, Faculdade de Medicina, Universidade de Sao Paulo, Sao Paulo, Brazil; Department of Orthopedic Surgery, Hospital Israelita Albert Einstein, Sao Paulo, Brazil, Phone: +5511982441913, e-mail: alexandrelemegodoy@gmail.com

How to cite this article: Godoy-Santos $A L$, Herrera-Pérez $M$, de Cesar Netto C, et al. Is Ankle Post-traumatic Osteoarthritis Inevitable after Malleolar Fractures? J Foot Ankle Surg (Asia Pacific) 2021;8(4): 180-187.

Source of support: Nil

Conflict of interest: None

\section{Quality of Joint Reduction and Fracture FIXATION}

\section{Lateral Malleolar Fracture}

The level of fracture by the Weber classification interferes with clinical follow-up outcome: $82 \%$ type Weber A, 83\% type Weber B, 70\% type Weber C. $^{13}$

Open anatomic reduction and rigid internal fixation of unstable lateral malleolar fractures are indicated to avoid shortening, lateral displacement, and external rotation of the fibula, ${ }^{14}$ to maintain joint contact pressures at normal levels.

(o) The Author(s). 2021 Open Access This article is distributed under the terms of the Creative Commons Attribution 4.0International License (https://creativecommons. org/licenses/by-nc/4.0/), which permits unrestricted use, distribution, and non-commercial reproduction in any medium, provided you give appropriate credit to the original author(s) and the source, provide a link to the Creative Commons license, and indicate if changes were made. The Creative Commons Public Domain Dedication waiver (http://creativecommons.org/publicdomain/zero/1.0/) applies to the data made available in this article, unless otherwise stated. 


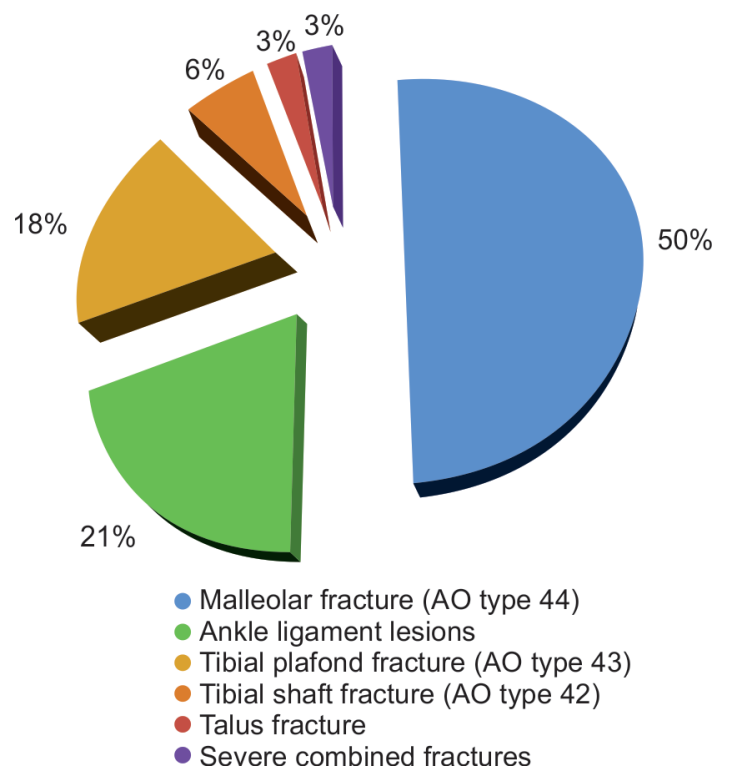

Fig. 1: Etiological factors distribution of post-traumatic ankle osteoarthritis
The fixation options include tubular lateral or posterolateral plates, non-locked or locked plates, lateral anatomic distal fibular plate, and distal fibula intramedullary nail (Fig. 2). 13,15

\section{Medial Malleolar Fracture}

The medial malleolar fractures can be classified as horizontal (Aavulsion; $\mathrm{B}$ - between the apex and the plafond, and $\mathrm{C}$ - at the plafond) or vertical (type D). ${ }^{16,17}$

The role of clinical and biomechanical aspects of the medial malleolus and ligamentous structures has been well studied. Some authors have shown in isolated medial malleolar osteotomy a decrease in medial articular contact pressure of $27.8 \%$ following fixation when compared with non-fixation. ${ }^{18,19}$

Open anatomic reduction and lag screw fixation is indicated for horizontal medial malleolar fracture, on the other hand, the lag screw through buttress plate technique is recommended for vertical medial malleolar fracture. The new implant's design minimizes pain related to plate and screws prominence (Fig. 3). ${ }^{16-19}$

\section{Posterior Malleolar Fracture}

Studies show significantly worst clinical outcomes after a surgical of ankle fractures involving PM comparing with patients without this lesion. ${ }^{20,21}$
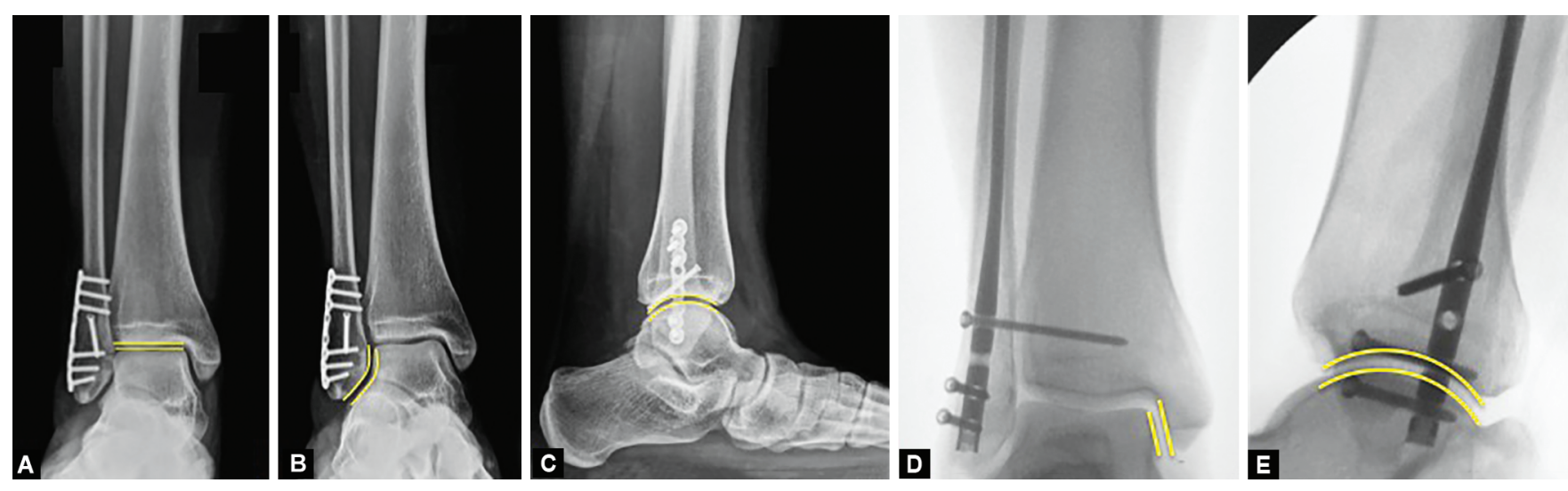

Figs $2 \mathrm{~A}$ to E: (A to C) AP, Mortise and lateral view radiograph showing lag screw and plate fixation for simple lateral malleolar fracture restoring joint congruency parameter; ( $D$ and $E$ ) AP and lateral view fluoroscopy showing intramedullary nail fixation for simple lateral malleolar fracture restoring joint congruency parameters
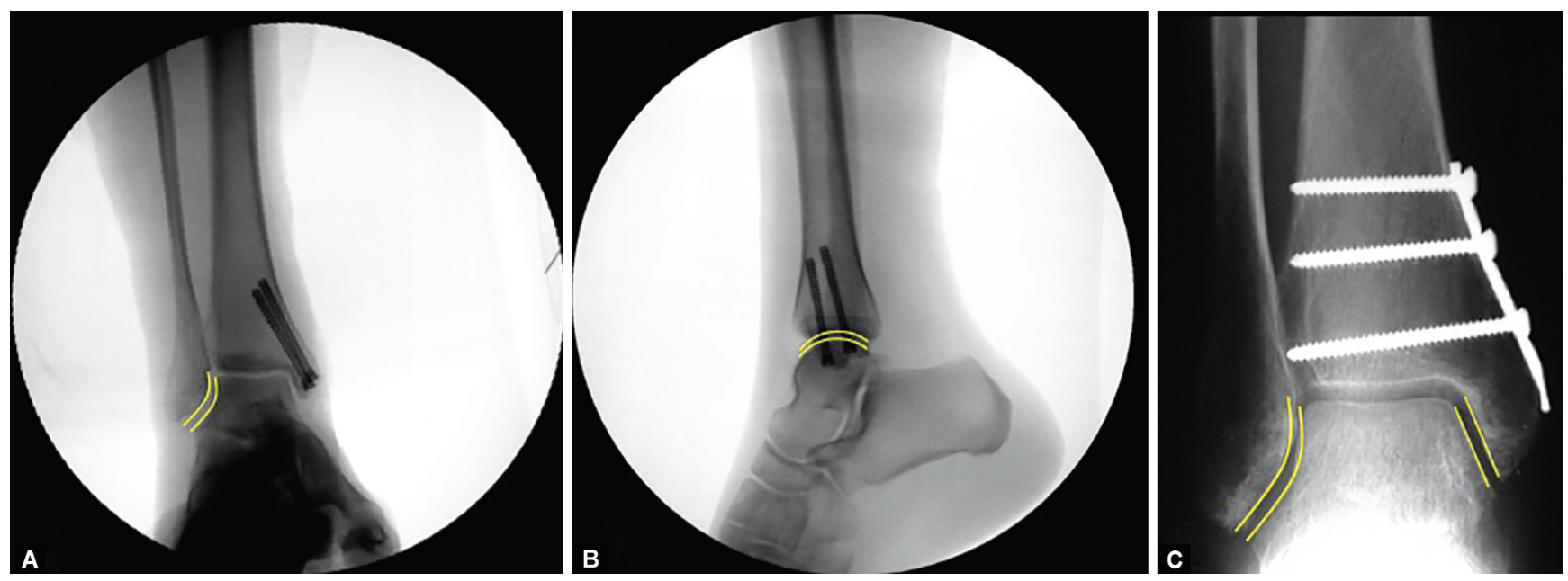

Figs $3 \mathrm{~A}$ to $\mathrm{C}$ : (A and B) AP and lateral view fluoroscopy showing 2 lag screws fixation for oblique simple medial malleolar fracture restoring joint congruency parameters; (C) AP view radiograph showing lag screw through buttress plate for vertical simple medial malleolar fracture 

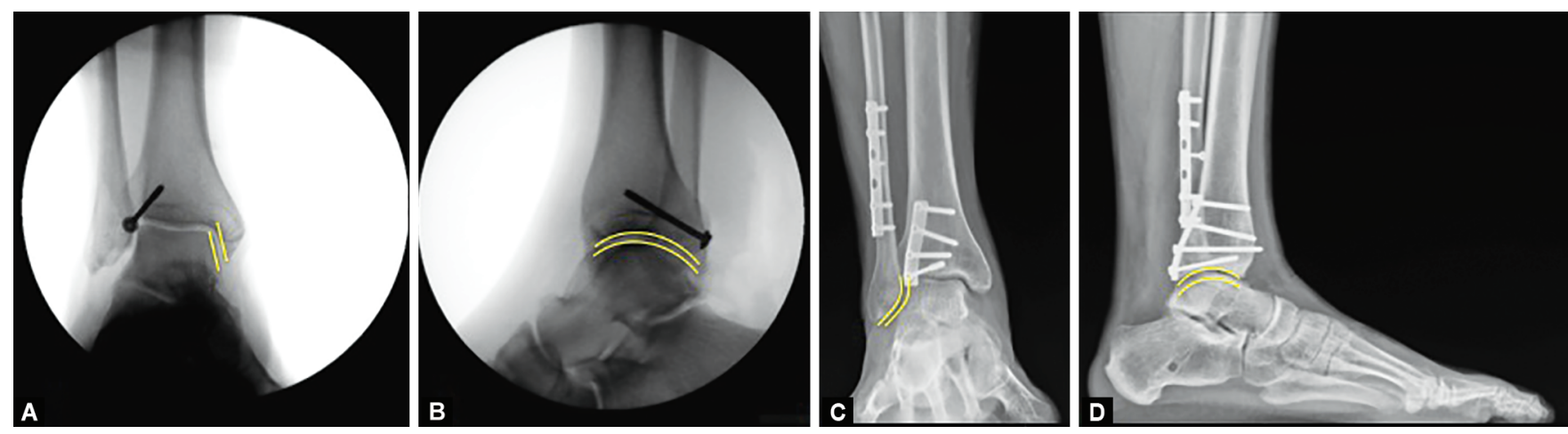

Figs 4A to D: (A and B) AP and lateral view fluoroscopy showing lag screw fixation for small posterior malleolar fracture; (C and D) AP and lateral view radiograph showing lag screw through buttress plate for large posterior malleolar fracture

There is already a consensus in the literature to recommend MP reduction and fixation whenever it represents a joint instability factor (sagittal and coronal plane) and interferes with the anatomical reduction of the syndesmosis and its stability, regardless of the size of the bone fragment.

In the 1920s, Lounsbury, Metz, ${ }^{22}$ and Leveuf ${ }^{23}$ published the first PM fixation reports.

Currently, the Bartonícek et al.'s Classification System based on 3D CT scanning represents a useful tool in decision making. ${ }^{24}$

Open reduction and internal fixation (ORIF) of PM fragment results in a decrease of up to $60 \%$ in trans-syndesmotic fixation needs as well as better quality of distal tibiofibular joint congruency compared with closed reduction and anteroposterior screw or fractures in untreated PM. ${ }^{25}$

Posterior malleolar fracture reduction and fixation could be performed: ${ }^{26,27}$

- Direct through posterolateral or posteromedial approaches and lag screws - small fragment or with plate buttresses and lag screw (lag screw through the plate or outside the plate)-large fragment.

- Indirect approach is more difficult to evaluate the reduction and soft tissue interposition could be an issue, usually, the sagittal lag screws are inserted through separate incisions.

In the study of a specimen, PM fixation presented superior biomechanical joint stability (70\%) compared with transsyndesmotic fixation (40\%). ${ }^{28}$

Direct reduction and posterior to anterior fixation with screws or a plate + screw allow greater biomechanical joint stability when compared with indirect reduction and anterior to posterior fixation (Fig. 4). ${ }^{29,30}$

\section{Residual Ligament Instability \\ Syndesmosis}

Syndesmosis injury can occur with almost any fracture pattern, approximately up to $23 \%$ of all ankle fractures. ${ }^{31,32}$

All four ligaments that compound syndesmosis complex are:

- Anterior inferior tibiofibular ligament (AITFL).

- Interosseous membrane ligament (IOM).

- Transverse tibiofibular ligament (TTFL).

- Posterior inferior tibiofibular ligament (PITFL).

After bone fixation, the first step is to check for residual syndesmotic instability in the absence of evident instability.
Undiagnosed and not well reduced syndesmotic instability represent determining factors for a poor clinical outcome.

There are basically three intraoperative reliable dynamic intraoperative tests described in the literature:

- Worldwide used as a clinical test for deltoid ligament lesion and medial ankle instability, the external rotation stress test, ${ }^{33,34}$ remains not standardized in the diagnosis of isolated distal tibiofibular. ${ }^{35,36}$

- Some authors have shown that measurement of sagittal instability allowed by the Cotton test or the Hook test is more sensitive than for coronal instability. This test has high specificity but low sensitivity. ${ }^{37-41}$

The simple Tap Test shows good sensitivity, specificity, and accuracy in the diagnosis of coronal syndesmotic instability. ${ }^{41}$

\section{Radiographic Findings}

There are three (Fig. 5) consensus radiographic measures used to evaluate residual syndesmosis instability intraoperatively after bone fixation using conventional fluoroscopy anteroposterior and mortise view: ${ }^{39}$

- The normal tibiofibular clear space (TFCS) is $<6 \mathrm{~mm}$.

- The normal tibiofibular overlap (TFO) is $<2 \mathrm{~mm}$.

- The medial clear space (MCS) is $<6 \mathrm{~mm}$.

These radiographic parameters show $47 \%$ sensitivity and $100 \%$ specificity compared with magnetic resonance image. ${ }^{40-44}$

It is recommended that, after bone fixation, a syndesmosis diastasis of $>2 \mathrm{~mm}$ be reduced and fixed.

\section{Rigid Fixation}

There is no clinically significant difference for the treatment of syndesmosis instability comparing:

- One vs two syndesmotic screws. ${ }^{45,46}$

- Tricortical vs quadricortical screws. ${ }^{47,48}$

- Trans-syndesmotic vs supra-syndesmotic screws. ${ }^{49}$

- Metal screws vs bioabsorbable screws. ${ }^{50-53}$

Biomechanical studies comparing $4.5 \mathrm{~mm}$ screw vs $3.5 \mathrm{~mm}$ screw show divergent results. ${ }^{54,55}$

A small plate connecting two syndesmotic screws increases mechanical strength in poor-quality bone. ${ }^{56}$

The lowest tension for screws positioned between $3 \mathrm{~cm}$ and 40 $\mathrm{cm}$ above the tibiotarsal joint line was advocated by McBryde et al. ${ }^{57}$ 

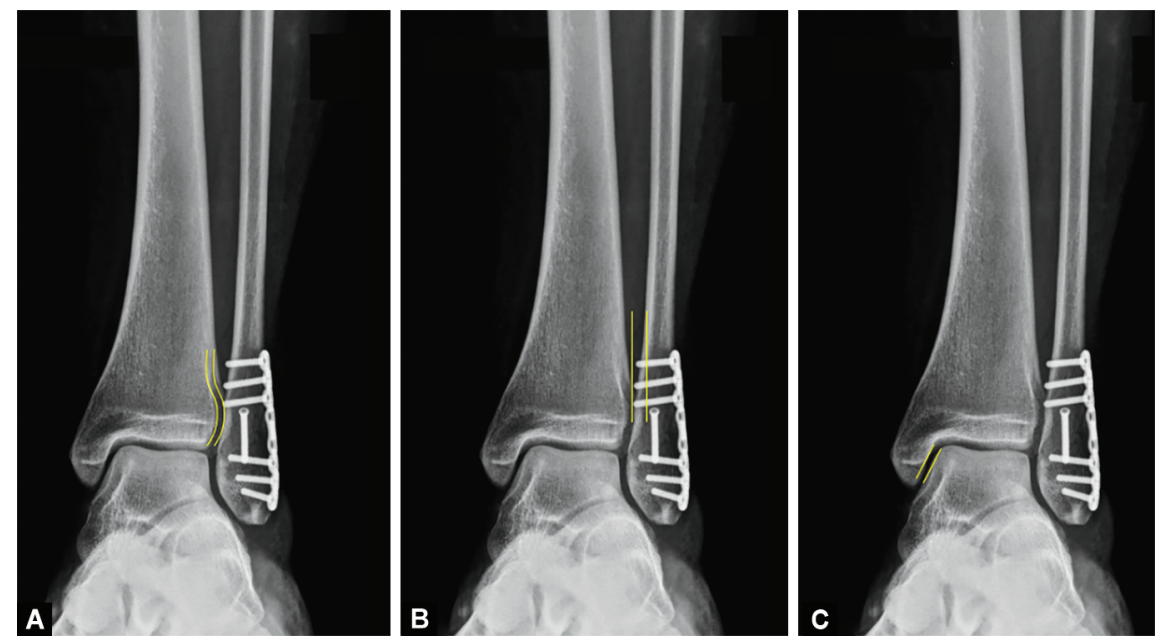

Figs 5A to C: (A) Tibiofibular clear space (TFCS); (B) Tibiofibular overlap (TFO); (C) Medial clear space (MCS)

However, Seitz et al. showed that a screw positioned $2 \mathrm{~cm}$ from this joint line resulted in less enlargement of the syndesmosis. ${ }^{58}$

\section{Flexible Fixation}

The suture button fixation provides stability and allows distal fibula-tibial joint movement closed to the physiological one. ${ }^{59}$ This option is equivalent to a $3.5 \mathrm{~mm}$ tricortical $\mathrm{screw}^{60}$ or a 4.5 mm quadricortical screw. ${ }^{61}$ However, the functional results in the short-term do not show relevant differences. ${ }^{62}$

Flexible fixation shows less indication for implant removal. While comparing rigid and flexible fixation the only variable that had a significant influence on the functional outcome was the anatomical reduction of the distal fibula in the tibial notch. ${ }^{63}$

\section{Deltoid Ligament}

The treatment of deltoid injuries in malleolar fractures remains without consensus.

The role of the deltoid ligament is fundamental in normal ankle biomechanics, ${ }^{64-66}$ its superficial component participates in the hindfoot eversion restriction, and its deep component participates in the talus external rotation restriction. ${ }^{64-67}$

\section{How to Determine when Surgical Treatment is Required for Deltoid Ligament Injury Related to Medial Malleolar Fracture?}

\section{Physical Exam}

Some authors observed that the classic findings on clinical examination showed a poor correlation with deltoid complex insufficiency. ${ }^{34,68,69}$

\section{Simple Radiography}

The measurement of the MCS outside the normal range on static radiography (without stress) mortise view is a method used to identify residual medial instability. ${ }^{34,69,70}$ However, the normal MCS does not exclude residual medial instability.

\section{Stress or Gravity Stress Radiography}

Park et al. ${ }^{71}$ and Michelson et al. ${ }^{72}$ performed similar studies regarding the radiographic findings of gravitational stress, the authors observed that the medial free space of $5 \mathrm{~mm}$ is a good parameter for damage to the deep component of the deltoid complex.

\section{Magnetic Resonance Image}

In the treatment of malleolar fractures, magnetic resonance still does not show a standardized role in therapeutic decision-making regarding the deltoid complex.

Nortunen et al. observed that all volunteers with isolated fractures of the fibula by SER mechanisms showed positive magnetic resonance imaging (MRI) findings for ligament involvement of the deltoid. On the other hand, they observed high variation in MCS in volunteers with similar MRI findings, as well as low interobserver reliability for MRI compared with the stress test. Thus, they do not recommend $\mathrm{MRI}$ for therapeutic decision-making. ${ }^{73}$

Warner et al. showed that magnetic resonance image allows correct diagnosis of ligament injuries associated with ankle fracture in $94 \%$ of patients. ${ }^{74}$

\section{Treatment}

Salameh et al. and Dabash et al. ${ }^{75,76}$ concluded that deltoid ligament repair in Weber type $\mathrm{B}$ and $\mathrm{C}$ malleolar fractures confers:

- Better joint reduction.

- Lower pain score.

- Similar complication rates.

- No difference in functional outcome.

\section{Initial Damage to Joint Tissues}

Immediately after trauma, articular chondrocytes are influenced by various inflammatory chemokines, including TNF- $a, \mathrm{IL}-1 \beta$, and metalloproteinases (Fig. 6). ${ }^{77}$

In these contexts, minimizing the acute injury and its progression at the tissue and molecular level should be targeted along with the macroscopic alterations induced by the trauma to prevent the evolution to post-traumatic OA.

Dingle et al. first studied in vivo the detrimental effects of cytokines on articular tissues. ${ }^{78}$ In an earlier study, the same author also stated that synovium affected the cartilage in two ways: ${ }^{79}$

- Direct action on the matrix, possibly by secreted proteinases, like collagenase. 

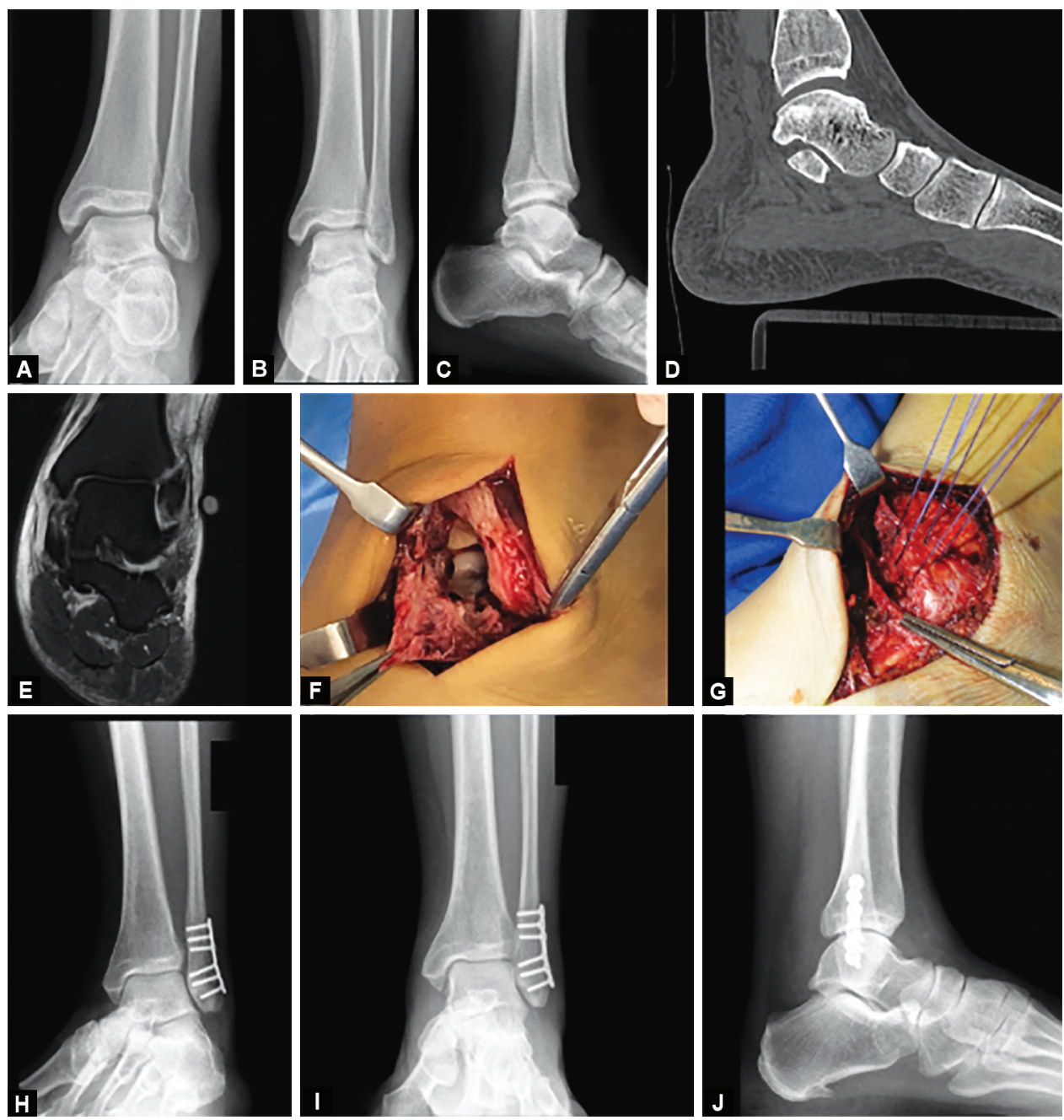

Figs 6A to J: (A to C) Preoperative X-rays (Mortise, anteroposterior, and lateral view) showing a displaced isolated unimalleolar lateral fracture and increased medial clear space; (D) CT showing anteromedial tibiotalar articular divergent; (E) MRI showing complete deltoid ligament rupture (superficial and depth component); (F and G) Intraoperative clinical aspect showing deltoid lesion and repair; (H to J) Last follow-up X-rays (Mortise, anteroposterior, and lateral view) demonstrate bone union in an anatomic position, perfect alignment of lateral and medial tibiotalar joint lines

- Indirect action mediated through the living chondrocytes which produce acidic proteinases of the lysosomal system.

Adams et al. observed an elevation of pro-inflammatory cytokines in synovial fluid in a fractured ankle compared to an uninjured ankle at different post-injury times. ${ }^{80-82}$ Godoy-Santos et al. analyzing the cellularity and synovial profile in patients with acute ankle fractures, the authors also observed high concentrations of cytokines in the synovial fluid, in addition to the accumulation of collagen and proteoglycans in the synovial tissue. ${ }^{83}$

A recent analysis by Leimer et al. revealed a significant elevation of 19 amino acids metabolites in ankle fracture in comparison to the contralateral sides. ${ }^{84}$

These results show that pathological changes happen simultaneously to different articular tissues following ankle fractures.

Traumatic aggression to synovial tissue results in the release of pro-inflammatory substances, which reach the chondral tissue through the synovial fluid, causing high cell death of chondrocytes. $^{85}$
Another pathway leading to damage to synovial tissue and cartilage involves complement activation. ${ }^{86}$

Finally, activation of both pathways in joint tissues and fluids leads to increased genetic modulation for the production of proinflammatory substances. ${ }^{87}$

\section{Detecting Early Osteoarthritic Changes in the Ankle Joint}

\section{Biomarkers}

Inflammation biomarkers may be the first identifier of PTOA. Although studies show that these substances can be identified in blood, urine, and synovial fluid, there is no consensus on the ideal marker. $^{88}$

IL-2, IL-6, IL-8, IL-10, IL-17, MMP-1, MMP-2, MMP-3, and TNF-a are biomarkers under study. ${ }^{80-84}$ However, it is not a routine yet.

\section{Imaging}

Magnetic resonance imaging is an adequate option for the early detection of OA. In this sense, the new cartilage mapping acquisition 
allows us to visualize alterations in the microstructure, in the composition of the extracellular matrix, and in the chondrocytes. T1 $\rho$ allows proteoglycan content assessment and T2 relaxation allows collagen organization assessment. 89,90

T2 mapping shows low sensitivity for deep chondral tissue layers. ${ }^{91,92}$

For the analysis of chondral damage extension and its biological activity, single-photon emission computed tomography (SPECT-CT) shows high interobserver and intraobserver reliability compared with a conventional $\mathrm{CT}^{93,94}$

\section{Early Treatment}

Joint washing at the time of surgery to remove a hematoma, small bone fragments, and inflammatory substances involved in ankle joint degeneration seems to contribute to PTOA prevention. ${ }^{80-84}$

Some medications can modulate chondrocyte metabolism; on the one hand, promoting its proliferation and on the other, inhibiting cell death, e.g., lovastatin-induced proliferation and reduced apoptosis in an experimental study in rabbits, ${ }^{95}$ celecoxib and indomethacin reduced trauma-induced cell death in a study with impacted human cartilage. ${ }^{96,97}$

Although hyaluronan $(\mathrm{HA})$ has a proven role in chondrocyte apoptosis in already established $\mathrm{OA}^{98}$ there is no evidence of this action in acute fractures. In an in vitro study, the platelet-rich plasma (PRP) promoted cell proliferation and decreased cell death. ${ }^{99,100}$

Inflammatory modulators are potential therapeutic tools against intra-articular tissue degeneration. However, we have not yet identified solid evidence in the literature.

Randomized clinical trials and experimental studies of PTOA are needed to advance this area of knowledge. ${ }^{101-103}$

\section{Conclusion}

Post-traumatic ankle $\mathrm{OA}$ is avoidable and minimizable after malleolar fractures.

The key factors to prevent PTOA are:

- Anatomically reducing all three joints-tibiotalar, tibiofibular, and fibulotalar.

- Properly fixing fractures.

- Correctly restoring ligament stability.

The strategies to modulate initial damage to joint tissues are still under investigation.

\section{References}

1. Waterman BR, Owens BD, Davey S, et al. The epidemiology of ankle sprains in the United States. J Bone Joint Surg Am 2010;92(13):22792284. DOI: 10.2106/JBJS.I.01537.

2. Court-Brown CM, Caesar B. Epidemiology of adult fractures: a review. Injury 2006;37(8):691-697. DOI: 10.1016/j.injury.2006.04.130.

3. Bugler KE, Clement ND, Duckworth AD, et al. Open ankle fractures: who gets them and why? Arch Orthop Trauma Surg 2015;135(3):297303. DOI: 10.1007/s00402-014-2140-3.

4. Elsoe R, Ostgaard SE, Larsen P. Population-based epidemiology of 9767 ankle fractures. Foot Ankle Surg 2018;24(1):34-39. DOI: 10.1016/j. fas.2016.11.002.

5. Miller AN, Paul O, Boraiah S, et al. Functional outcomes after syndesmotic screw fixation and removal. J Orthop Trauma 2010;24(1):12-16. DOI: 10.1097/BOT.0b013e3181c6e199.

6. Goldberg AJ, MacGregor A, Dawson J, et al. The demand incidence os symptomatic ankle osteoarthritis presenting to foot and ankle surgeons in the United Kingdom. Foot (Edin) 2012;22(3):163-166. DOI: 10.1016/j.foot.2012.02.005.

7. Valderrabano V, Horisberger M, Russell I, et al. Etiology of ankle osteoarthritis. Clin Orthop Relat Res 2009;467(7):1800-1806. DOI: 10.1007/s11999-008-0543-6.

8. Aurich M, Squires GR, Reiner A, et al. Differential matrix degradation and turnover in early cartilage lesions of human knee and ankle joints. Arthritis Rheum 2005;52(1):112-119. DOI: 10.1002/art.20740.

9. Treppo S, Koepp H, Quan EC, et al. Comparison of biomechanical and biochemical properties of cartilage from human knee and ankle pairs. J Orthop Res 2000;18(5):739-748. DOI: 10.1002/jor.1100180510.

10. Pott P. Some few general remarks on fractures and dislocations. 1758. Clin Orthop Relat Res 2007;458:40-41. DOI: 10.1097/ BLO.0b013e31803dd063.

11. Lane WA. The classic: the operative treatment of fractures. 1909. Clin Orthop Relat Res 2009;467(8):1944-1947.

12. Broos PL, Bisschop AP. Operative treatment of ankle fractures in adults: correlation between types of fracture and final results. Injury 1991;22(5):403-406. DOI: 10.1016/0020-1383(91)90106-o.

13. Aiyer AA, Zachwieja EC, Lawrie CM, et al. Management of isolated lateral malleolus fractures. J Am Acad Orthop Surg 2019;27(2):50-59. DOI: 10.5435/JAAOS-D-17-00417.

14. Thordarson DB, Motamed S, Hedman T, et al. The effect of fibular malreduction on contact pressures in an ankle fracture malunion model. J Bone Joint Surg Am 1997;79(12):1809-1815. DOI: 10.2106/00004623-199712000-00006.

15. Giordano V, Boni G, Godoy-Santos AL, et al. Nailing the fibula: alternative or standard treatment for lateral malleolar fracture fixation? A broken paradigm. Eur J Trauma Emerg Surg 2020. DOI: 10.1007/s00068-020-01337-wEpub ahead of print.

16. Herscovici D, Scaduto JM, Infante A. Conservative treatment of isolated fractures of the medial malleolus. J Bone Joint Surg $[\mathrm{Br}]$ 2007;89-B:89-93.

17. Müller ME, Nazarian $S$, Koch $P$, et al. The comprehensive classification of fractures of long bones. Springer-Verlag; 1990.

18. Carter TH, Duckworth AD, White TO. Medial malleolar fractures: current treatment concepts. Bone Joint J 2019;101-B(5):512-521. DOI: 10.1302/0301-620x.101B5.BJJ-2019-0070.

19. Lareau CR, Bariteau JT, Paller DJ, et al. Contribution of the medial malleolus to tibiotalar joint contact characteristics. Foot Ankle Spec 2015;8(1):23-28. DOI: 10.1177/1938640014546862.

20. Winters K. Functional outcome of surgery for fractures of the ankle. N Z Med J 2009;122(1289):57-62.

21. Day GA, Swanson CE, Hulcombe BG. Operative treatment of ankle fractures: a minimum ten-year follow-up. Foot Ankle Int 2017;22:102106.

22. Lounsbury BF, Metz AR. Lipping fracture of lower articular end of tibia. Arch Surg 1922;5(3):678-690. DOI: 10.1001/ archsurg.1922.01110150231010.

23. Leveuf J. Traitment Des Fractures Et Luxations Des Membres. Paris: Masson; 1925.

24. Bartonícek J, Rammelt S, Tucek M. Posterior malleolar fractures: changing concepts and recent developments. Foot Ankle Clin 2017;22(1):125-145. DOI: 10.1016/j.fcl.2016.09.009.

25. Baumbach SF, Herterich V, Damblemont A, et al. Open reduction and internal fixation of the posterior malleolus fragment frequently restores syndesmotic stability. Injury 2019;50(2):564-570. DOI: 10.1016/j.injury.2018.12.025.

26. https://surgeryreference.aofoundation.org/orthopedic-trauma/ adult-trauma/malleoli.

27. Rammelt S, Obruba P. An update on the evaluation and treatment of syndesmotic injuries. Eur J Trauma Emerg Surg 2015;41(6):601-614. DOI: 10.1007/s00068-014-0466-8.

28. Gardner MJ, Brodsky A, Briggs SM, et al. Fixation of posterior malleolar fractures provides greater syndesmotic stability. Clin Orthop Relat Res 2006;447:165-171. DOI: 10.1097/01.blo.0000203489. 21206.a9. 
29. Rammelt S, Zwipp H, Mittlmeier T. Operative treatment of pronation fracture-dislocations of the ankle [German]. Operat Orthop Traumatol 2013;25(3):273-291. DOI: 10.1007/s00064-013-0235-6.

30. Weber M. Trimalleolar fractures with impaction of the posteromedial tibial plafond: implications for talar stability. Foot Ankle Int 2004;25(10):716-727. DOI: 10.1177/107110070402501005.

31. Harper MC, Hardin G. Posterior malleolar fractures of the ankle associated with external rotation-abduction injuries: results with and without internal fixation. J Bone Joint Surg Am 1988;70(9):1348-1356. DOI: 10.2106/00004623-198870090-00012.

32. Haper MC. Instability of the distal tibiofibular syndesmosis after bimalleolar and trimalleolar ankle fractures. J Bone Joint Surg Am 1984;66(8):1319-1320. DOI: 10.2106/00004623-198466080-00028.

33. Tornetta P. Competence of the deltoid ligament in bimalleolar ankle fractures after medial malleolar fixation. J Bone Joint Surg Am 2000;82(6):843-848. DOI: 10.2106/00004623-200006000-00011.

34. van den Bekerom MP, Mutsaerts EL, van Dijk CN. Evaluation of the integrity of the deltoid ligament in supination external rotation ankle fractures: a systematic review of the literature. Arch Orthop Trauma Surg 2009;129(2):227-235. DOI: 10.1007/s00402-008-0768-6.

35. Stoffel K, Wysocki D, Baddour E, et al. Comparison of two intraoperative assessment methods for injuries to the ankle syndesmosis. A cadaveric study. J Bone Joint Surg Am 2009;91(11):2646-2652. DOl: 10.2106/JBJS.G.01537.

36. Monga P, Kumar A, Simons A, et al. Management of distal tibio-fibular syndesmotic injuries: a snapshot of current practice. Acta Orthop Belg 2008;74(3):365-369.

37. Cotton F. Fractures and joint dislocations. Philadelphia, PA: WB Saunders; 1910. p. 549.

38. Mizel MS. Technique tip: a revised method of the cotton test for intra-operative evaluation of syndesmotic injuries. Foot Ankle Int 2003;24(1):86-87. DOI: 10.1177/107110070302400115.

39. Krähenbühl N, Weinberg MW, Davidson NP, et al. Imaging in syndesmotic injury: a systematic literature review. Skeletal Radiol 2018;47(5):631-648. DOI: 10.1007/s00256-017-2823-2.

40. Candal-Couto JJ, Burrow D, Bromage S, et al. Instability of the tibiofibular syndesmosis: have we been pulling in the wrong direction? Injury 2004;35(8):814-818. DOI: 10.1016/j.injury.2003.10.013.

41. Xenos JS, Hopkinson WJ, Mulligan ME, et al. The tibiofibular syndesmosis. Evaluation of the ligamentous structures, methods of fixation, and radiographic assessment. J Bone Joint Surg Am 1995;77(6):847-856. DOI: 10.2106/00004623-199506000-00005.

42. de Cesar Netto C, Pinto M, Roberts L, et al. Intraoperative tap test for coronal syndesmotic instability: a cadaveric study. Injury 2018;49(10):1758-1762. DOI: 10.1016/j.injury.2018.08.005.

43. Pakarinen $\mathrm{H}$, Flinkkila $\mathrm{T}$, Ohtonen $\mathrm{P}$, et al. Intraoperative assessment of the stability of the distal tibiofibular joint in supination-external rotation injuries of the ankle: sensitivity, specificity, and reliability of two clinical tests. J Bone Joint Surg Am 2011;93(22):2057-2061. DOI: 10.2106/JBJS.J.01287.

44. Hermans JJ, Wentink N, Beumer A, et al. Correlation between radiological assessment of acute ankle fractures and syndesmotic injury on MRI. Skelet Radiol 2012;41(7):787-801. DOI: 10.1007/s00256011-1284-2.

45. Høiness P, Stromsøe K. Tricortical versus quadricortical syndesmosis fixation in ankle fractures: a prospective, randomized study comparing two methods of syndesmosis fixation. J Orthop Trauma 2004;18(6):331-337. DOI: 10.1097/00005131-200407000-00001.

46. Wikerøy AKB, Høiness PR, Andreassen GS, et al. No difference in functional and radiographic resuts 8.4 years after quadricortical compared with tricortical syndesmosis fixation in ankle fractures. J Orthop Trauma 2010;24(1):17-23.DOI: 10.1097/BOT.0b013e3181bedca1.

47. Beumer A, Campo MM, Niesing R, et al. Screw fixation of the syndesmosis: a cadaver model comparing stainless steel and titanium screws and three and four cortical fixation. Injury 2005;36(1):60-64. DOI: 10.1016/j.injury.2004.05.024.

48. Moore JA. Jr, Shank JR, Morgan SJ, et al. Syndesmosis fixation: a comparison of three and four cortices of screw fixation without hardware removal. Foot Ankle Int 2006;27(8):567-572. DOI: 10.1177/107110070602700801.

49. Kukreti S, Faraj A, Miles JN. Does position of syndesmotic screw affect functional and radiological outcome in ankle fractures? Injury 2005;36(9):1121-1124. DOI: 10.1016/j.injury.2005.01.014.

50. Ahmad J, Raikin SM, Pour AE, et al. Bioabsorbable screw fixation of the syndesmosis in unstable ankle injuries. Foot Ankle Int 2009;30(2):99105. DOI: 10.3113/FAI-2009-0099.

51. Hovis WD, Kaiser BW, Watson JT, et al. Treatment of syndesmotic disruptions of the ankle with bioabsorbable screw fixation. J Bone Joint Surg Am 2002;84-A:26-31.

52. Thordarson DB, Samuelson M, Shepherd LE, et al. Bioabsorbable versus stainless steel screw fixation of the syndesmosis in pronationlateral rotation ankle fractures: a prospective randomized trial. Foot Ankle Int 2001;22(4):335-338. DOI: 10.1177/107110070102200411.

53. Hansen $M$, Le L, Wertheimer $S$, et al. Syndesmosis fixation: analysis of shear stress via axial load on $3.5-\mathrm{mm}$ and $4.5-\mathrm{mm}$ quadricortical syndesmotic screws. J Foot Ankle Surg 2006;45(2):65-69. DOI: 10.1053/j.jfas.2005.12.004.

54. Thompson MC, GesinkDS. Biomechanical comparison of syndesmosis fixation with 3.5- and 4.5-millimeter stainless steel screws. Foot Ankle Int 2000;21(9):736-741. DOI: 10.1177/107110070002100904.

55. Gardner R, Yousri T, Holmes F, et al. Stabilization of the syndesmosis in the maisonneuve fracture-a biomechanical study comparing 2-hole locking plate and quadricortical screw fixation. J Orthop Trauma 2013;27(4):212-216. DOI: 10.1097/BOT.0b013e31825cfac2.

56. Verim O, Serhan Er M, Altinel L, et al. Biomechanical evaluation of syndesmotic screw position: a finite-element analysis. J Orthop Trauma 2014;28(4):210-215. DOI: 10.1097/BOT.0b013e3182a6df0a.

57. McBryde A, Chiasson B, Wilhelm A, et al. Syndesmotic screw placement: a biomechanical analysis. Foot Ankle Int 1997;18(5):262266. DOI: $10.1177 / 107110079701800503$.

58. Seitz WH, Bachner EJ, Abram LJ, et al. Repair of the tibio-fibular syndesmosis with a flexible implant. J Orthop Trauma 1991;5(1):78-82. DOI: 10.1097/00005131-199103000-00014.

59. Klitzman R, Zhao H, Zhang LQ, et al. Suture-button versus screw fixation of the syndesmosis: a biomechanical analysis. Foot Ankle Int 2010;31(1):69-75. DOI: 10.3113/FAI.2010.0069.

60. Thornes B, Walsh A, Hislop M, et al. Suture-endobutton fixation of ankle tibio-fibular diastasis: a cadaver study. Foot Ankle Int 2003;24(2):142-146. DOI: 10.1177/107110070302400208.

61. Thornes B, Shannon F, Guiney AM, et al. Suture-button syndesmosis fixation: accelerated rehabilitation and improved outcomes. Clin Orthop Relat Res 2005;431(431):207-212. DOI: 10.1097/01. blo.0000151845.75230.a0

62. Schepers T. Acute distal tibiofibular syndesmosis injury: a systematic review of suture-button versus syndesmotic screw repair. Int Orthop 2012;36(6):1199-1206. DOI: 10.1007/s00264-012-1500-2.

63. Naqvi GA, Cunningham P, Lynch B, et al. Fixation of ankle syndesmotic injuries: comparison of tightrope fixation and syndesmotic screw fixation for accuracy of syndesmotic reduction. Am J Sports Med 2012;40(12):2828-2835. DOI: 10.1177/0363546512461480.

64. Earll M, Wayne J, Brodrick C, et al. Contribution of the deltoid ligament to ankle joint contact characteristics: a cadaver study. Foot Ankle Int 1996;17(6):317-324. DOI: 10.1177/107110079601700604.

65. Rasmussen O, Kromann-Andersen C, Boe S. Deltoid ligament: Functional analysis of the medial collateral ligamentous apparatus of the ankle joint. Acta Orthop Scand 1983;54(1):36-44. DOI: $10.3109 / 17453678308992867$.

66. Clarke HJ, Michelson JD, Cox QG, et al. Tibio-talar stability in bimalleolar ankle fractures: a dynamic in vitro contact area study. Foot Ankle 1991;11(4):222-227. DOI: 10.1177/107110079101100407.

67. Harper MC. An anatomic study of the short oblique fracture of the distal fibula and ankle stability. Foot Ankle 1983;4(1):23-29. DOI: 10.1177/107110078300400106.

68. McConnell T, Creevy W, Tornetta P. Stress examination of supination external rotation-type fibular fractures. J Bone Joint Surg Am 2004;86-A:2171-2178. 
69. DeAngelis NA, Eskander MS, French BG. Does medial tenderness predict deep deltoid ligament incompetence in supination external rotation type ankle fractures? J Orthop Trauma 2007;21(4):244-247. DOI: 10.1097/BOT.0b013e3180413835.

70. Baird RA, Jackson ST. Fractures of the distal part of the fibula with associated disruption of the deltoid ligament: treatment without repair of the deltoid ligament. J Bone Joint Surg Am 1987;69(9):13461352. DOI: 10.2106/00004623-198769090-00007.

71. Park SS, Kubiak EN, Egol KA, et al. Stress radiographs after ankle fracture: the effect of ankle position and deltoid ligament status on medial clear space measurements. J Orthop Trauma 2006;20(1):11-18. DOI: 10.1097/01.bot.0000189591.40267.09.

72. Michelson JD, Varner KE, Checcone M. Diagnosing deltoid injury in ankle fractures: the gravity stress view. Clin Orthop Relat Res 2001(387):178-182. DOI: 10.1097/00003086-200106000-00024.

73. Nortunen S, Lepojärvi S, Savola O, et al. Stability assessment of the ankle mortise in supination-external rotation-type ankle fractures: lack of additional diagnostic value of MRI. J Bone Joint Surg Am 2014;96(22):1855-1862. DOI: 10.2106/JBJS.M.01533.

74. Warner SJ, Garner MR, Hinds RM, et al. Correlation between the LaugeHansen classification and ligament injuries in ankle fractures.J Orthop Trauma 2015;29(12):574-578. DOI: 10.1097/BOT.0000000000000393.

75. Salameh M, Alhammoud A, Alkhatib N, et al. Outcome of primary deltoid ligament repair in acute ankle fractures: a meta-analysis of comparative studies. Int Orthop 2020;44(2):341-347. DOI: 10.1007/ s00264-019-04416-9.

76. Dabash S, Elabd A, Potter E, et al. Adding deltoid ligament repair in ankle fracture treatment: is it necessary? a systematic review. Foot Ankle Surg 2019 Dec;25(6):714-720. DOI: 10.1016/j.fas.2018.11.001.

77. Pountos I, Giannoudis PV. Articular impaction injuries in the lower limb. EFORT Open Rev 2017;2(5):250-260. DOI: 10.1302/20585241.2.160072.

78. Dingle JT, Page Thomas DP, King B, et al. In vivo studies of articular tissue damage mediated by catabolin/interleukin 1. Ann Rheum Dis 1987;46(7):527-533. DOI: 10.1136/ard.46.7.527.

79. Dingle JT. Catabolin-A cartilage catabolic factor from synovium. Clin Orthop Relat Res 1981;156(156):219-231. DOI: 10.1097/00003086198105000-00033.

80. Adams SB, Setton LA, Bell RD, et al. Inflammatory cytokines and matrix metalloproteinases in the synovial fluid after intraarticular ankle fracture. Foot Ankle Int 2015;36(11):1264-1271. DOI: 10.1177/1071100715611176.

81. Adams SB, Reilly RM, Huebner JL, et al. Time-dependent effects on synovial fluid composition during the acute phase of human intraarticular ankle fracture. Foot Ankle Int 2017;38(10):1055-1063. DOI: $10.1177 / 1071100717728234$.

82. Adams SB, LeimerEM, Setton LA, etal. Inflammatory microenvironment persists after bone healing in intra-articular ankle fractures. Foot Ankle Int 2017;38(5):479-484. DOI: 10.1177/1071100717690427.

83. Godoy-Santos AL, Ranzoni L, Teodoro WR, et al. Increased cytokine levels and histological changes in cartilage, synovial cells and synovial fluid after malleolar fractures. Injury 2017;48(Suppl 4):S27-S33.

84. Leimer EM, Tanenbaum LM, Nettles DL, et al. Amino acid profile of synovial fluid following intra-articular ankle fracture. Foot Ankle Int 2018;39(10):1169-1177. DOI: 10.1177/1071100718786163.

85. Hügle T, Geurts J. What drives osteoarthritis?-synovial versus subchondral bone pathology. Rheumatology (Oxford) 2017;56(9):1461-1471. DOI: 10.1093/rheumatology/kew389.

86. Liu-Bryan R. Synovium and the innate inflammatory network in osteoarthritis progression. Curr Rheumatol Rep 2013;15(5):323. DOI: 10.1007/s11926-013-0323-5.
87. Kapoor M, Martel-Pelletier J, Lajeunesse D, et al. Role of proinflammatory cytokines in the pathophysiology of osteoarthritis. Nat Rev Rheumatol 2011;7(1):33-42. DOI: 10.1038/nrrheum.2010.196.

88. Catterall J, Stabler T, Flannery C, et al. Changes in serum and synovial fluid biomarkers after acute injury. Arthritis Res Ther 2010;12(6):R229. DOI: 10.1186/ar3216.

89. Akella SV, Regatte RR, Gougoutas AJ, et al. Proteoglycan-induced changes in T1rho-relaxation of articular cartilage at 4T. Magn Reson Med 2001;46(3):419-423. DOI: 10.1002/mrm.1208.

90. Menezes NM, Gray ML, Hartke JR, et al. T2 and T1rho MRI in articular cartilage systems. Magn Reson Med 2004;51(3):503-509. DOI: 10.1002/ mrm.10710.

91. Williams A, Qian Y, Bear D, et al. Assessing degeneration of human articular cartilage with ultra-short echo time (UTE) T2* mapping. Osteoarthritis Cartilage 2010;18(4):539-546. DOI: 10.1016/j. joca.2010.02.001.

92. Chu CR, Williams AA, West RV, et al. Quantitative magnetic resonance imaging UTE-T2* mapping of cartilage and meniscus healing after anatomic anterior cruciate ligament reconstruction. Am J Sports Med 2014;42(8):1847-1856. DOI: 10.1177/0363546514532227.

93. Barg A, Pagenstert Gl, Hügle T, et al. Ankle osteoarthritis: etiology, diagnostics, and classification. Foot Ankle Clin 2013;18(3):411-426. DOI: 10.1016/j.fcl.2013.06.001.

94. Pagenstert GI, Barg A, Leumann AG, et al. SPECT-CT imaging in degenerative joint disease of the foot and ankle. J Bone Joint Surg Br 2009;91(9):1191-1196. DOI: 10.1302/0301-620X.91B9.22570.

95. Zhou B, Chen D, Xu H, et al. Proliferation of rabbit chondrocyte and inhibition of IL-1b-induced apoptosis through MEK/ERK signaling by statins. In Vitro Cell Dev Biol Anim 2017;53(2):124-131. DOI: 10.1007/ s11626-016-0086-1.

96. Pountos I, Giannoudis PV, Jones E, et al. NSAIDS inhibit in vitro MSC chondrogenesis but not osteogenesis: implications for mechanism of bone formation inhibition in man. J Cell Mol Med 2011;15(3):525-534. DOI: 10.1111/j.1582-4934.2010.01006.x.

97. Jeffrey JE, Aspden RM. Cyclooxygenase inhibition lowers prostaglandin E2 release from articular cartilage and reduces apoptosis but not proteoglycan degradation following an impact load in vitro. Arthritis Res Ther 2007;9(6):R129. DOI: 10.1186/ar2346.

98. Euppayo T, Siengdee P, Buddhachat K, et al. Effects of low molecular weight hyaluronan combined with carprofen on canine osteoarthritis articular chondrocytes and cartilage explants in vitro. In Vitro Cell Dev Biol Anim 2015;51(8):857-865. DOI: 10.1007/s11626-015-9908-9.

99. Pascual Garrido C, Hakimiyan AA, Rappoport L, et al. Anti-apoptotic treatments prevent cartilage degradation after acute trauma to human ankle cartilage. Osteoarthritis Cartilage 2009;17(9):1244-1251. DOI: 10.1016/j.joca.2009.03.007.

100. Moussa M, Lajeunesse D, Hilal G, et al. Platelet rich plasma (PRP) induces chondroprotection via increasing autophagy, antiinflammatory markers, and decreasing apoptosis in human osteoarthritic cartilage. Exp Cell Res 2017;352(1):146-156. DOI: 10.1016/j.yexcr.2017.02.012.

101. Delco ML, Kennedy JG, Bonassar LJ, et al. Post-traumatic osteoarthritis of the ankle: a distinct clinical entity requiring new research approaches. J Orthop Res 2017;35(3):440-453. DOI: 10.1002/jor.23462.

102. Anderson DD, Chubinskaya S, Guilak F, et al. Post-traumatic osteoarthritis: improved understanding and opportunities for early intervention. J Orthop Res 2011;29(6):802-809. DOI: 10.1002/ jor.21359.

103. Lotz MK, Kraus VB. New developments in osteoarthritis. Posttraumatic osteoarthritis: pathogenesis and pharmacological treatment options. Arthritis Res Ther 2010;12(3):211-211. DOI: 10.1186/ar3046. 